\title{
Avaliação de manchas em grãos de amendoim produzidos sob epidemia severa de mancha anelar
}

\section{http://dx.doi.org/10.17648/sas.v1i1.14}

Taís de Moraes Falleiro Suassuna (D)

Programa de Melhoramento do Amendoim - Embrapa, Santo Antônio de Goiás, GO, e-mail: tais.suassuna@embrapa.br.

Jair Heuert ${ }^{(D)}$

Programa de Melhoramento do Amendoim - Embrapa, Santo Antônio de Goiás, GO, e-mail: jair.heuert@embrapa.br.

Kennedy Brunno de Brito Martins (iD

Programa de Melhoramento do Amendoim - Embrapa, Santo Antônio de Goiás, GO, e-mail: kennedybrunno22@gmail.com.

Amenco Peanuts, e-mail: marcel.rodrigo@amenco.com.br, Tupã, SP.

Marcel Rodrigo Bazanella (D)

Maxuel Fellipe Nunes Xavier (D)

Discente de Agronomia do IFMT Campus São Vicente - Centro de Referência de Campo Verde, Campo Verde, MT, e-mail: maxuelfellipe90@gmail.com.

Beatrice Peanuts, Tupã, SP; e-mail: rodolfo@beatricepeanuts.com.

Rodolfo Pires Ribeiro (D)

\section{RESUMO}

A mancha anelar é uma virose causada por espécies do gênero de Tospovirus, também pode causar manchas nos grãos de amendoim. Informações quanto aos sintomas nos grãos são escassos no Brasil. Devido a isso, objetivou-se avaliar manchas em grãos de amendoim produzidos sob elevada severidade de mancha anelar. Foram avaliadas 26 linhagens e a cultivar BRS 423 OL, desenvolvidas pelo Programa de Melhoramento do Amendoim da Embrapa, na safra 2019/20 em Tupã-SP, sob epidemia severa de mancha anelar. Cada parcela tinha duas linhas com três metros de comprimento espaçadas em 0,90 m entre linhas. As parcelas foram invertidas aos 122 dias após a semeadura. Foram coletadas quatro amostras de 200 gramas de cada genótipo, em delineamento inteiramente casualizado e identificados os grãos manchados com sintomas de mancha anelar (presença de manchas irregulares, avermelhamento, rachaduras nas películas e deformações nos grãos) e dos grãos sadios, para determinar a massa e a porcentagem de grãos manchados. A linhagem 18-2131 OL apresentou a menor massa e a menor porcentagem de grãos manchados (20,1\%); as linhagens 19-2584 OL, 18-2136 OL, 18-2042 OL e 18-2250 OL apresentaram menos de 30\% de manchas; a cultivar BRS $423 \mathrm{OL}$ apresentou menos de $32 \%$ de mancha nos grãos. A identificação de genótipos com menos sintomas nos grãos é importante para o desenvolvimento de cultivares de amendoim com melhor qualidade dos grãos.

Palavras-chave: Arachis hypogaea L.; Programa de Melhoramento; Qualidade dos Grãos; Virose.

\section{Evaluation of stains on peanut grains produced under severe ring stain epidemic}

\author{
ABSTRACT
}


The ring spot is a virus caused by species of the Tospovirus genus, it can also cause spots on peanut grains. Information on symptoms in grains is scarce in Brazil. Because of this, the objective was to evaluate stains on peanut grains produced under high severity of ring stain. 26 lines and the cultivar BRS 423 OL, developed by the Embrapa Peanut Breeding Program, were evaluated in the 2019/20 harvest in Tupã-SP, under a severe ring spot epidemic. Each plot had two lines with three meters in length spaced $0.90 \mathrm{~m}$ between lines. The plots were inverted at 122 days after sowing. Four samples of 200 grams of each genotype were collected, in a completely randomized design, and the grains stained with ring stain symptoms (presence of irregular stains, redness, cracks in the films and deformations in the grains) and healthy grains were identified to determine the mass and the percentage of spotted grains. The strain 18-2131 $O L$ had the lowest mass and the lowest percentage of spotted grains (20.1\%); strains 19-2584 $O L, 18-2136 O L, 18-2042 O L$ and 18-2250 OL showed less than $30 \%$ of spots; the BRS 423 OL cultivar showed less than $32 \%$ of grain stain. The identification of genotypes with less symptoms in the grains is important for the development of peanut cultivars with better grain quality.

Keywords: Arachis hypogaea L.; Improvement Program; Grain Quality; Virose.

\title{
Evaluación de manchas en granos de maní producidos bajo epidemia severa de manchas en anillo
}

\author{
RESUMEN
}

La mancha del anillo es un virus causado por especies del género Tospovirus, también puede causar manchas en los granos de maní. La información sobre los síntomas en los granos es escasa en Brasil. Debido a esto, el objetivo era evaluar las manchas en los granos de maní producidos bajo alta severidad de la mancha de anillo. Se evaluaron 26 líneas y el cultivar BRS 423 OL, desarrollado por el Programa de Mejoramiento de Maní Embrapa, en la cosecha 2019/20 en Tupã-SP, bajo una epidemia severa de mancha anular. Cada parcela tenía dos líneas con tres metros de longitud espaciadas 0.90 m entre líneas. Las parcelas se invirtieron a los 122 días después de la siembra. Se recogieron cuatro muestras de 200 gramos de cada genotipo, en un diseño completamente al azar, y se identificaron los granos manchados con síntomas de anillo (presencia de manchas irregulares, enrojecimiento, grietas en las películas $y$ deformaciones en los granos) y se identificaron granos sanos para determinar la masa. y el porcentaje de granos manchados. La cepa 18-2131 OL tuvo la masa más baja y el porcentaje más bajo de granos manchados (20.1\%); las cepas 19-2584 OL, 18-2136 OL, 18-2042 OL y 182250 OL mostraron menos del 30\% de las manchas; El cultivar BRS 423 OL mostró menos del $32 \%$ de la mancha de grano. La identificación de genotipos con menos síntomas en los granos es importante para el desarrollo de cultivares de maní con mejor calidad de grano.

Palabras clave: Arachis hypogaea L.; Programa de Mejoramiento; Calidad de Grano; Virosa.

\section{Introdução}

Os sintomas da mancha anelar mais conhecidos são descritos como presença de anéis cloróticos, clareamento das nervuras, afundamento internerval nos folíolos, definhamento e redução do crescimento das plantas, além de necrose apical (SUASSUNA et al., 2016).

No entanto, esta virose causada por espécies do gênero de Tospovirus também pode causar sintomas nos grãos, caracterizados como manchas irregulares e descoloração da testa (película), que também pode apresentar coloração avermelhada e estrias (rachaduras), além de 
enrugamento, deformação dos grãos também é relatada. Apesar de apresentar sintomas nos grãos, esta virose não é transmitida pelos grãos (PAPPU et al., 1999).

Epidemias de mancha anelar, têm sido relatadas na Alta Paulista, região oeste do estado de São Paulo, nos últimos anos, causando redução na produção (RIBEIRO et al., 2017; RIBEIRO et al., 2019). Durante a safra 2017/18, foram coletadas amostras de folíolos de plantas com sintomas de anéis cloróticos, clareamento das nervuras, mosaico nas folhas, afundamento do tecido internerval, necrose na parte apical e crescimento atrofiado, em Herculândia-SP. Por meio de RT-PCR e utilizando primers específicos, foram detectadas as espécies Groundnut ring spot virus (GRSV) e Tomato chlorotic spot virus (TCSV) (MAGALHÃES et al., 2019).

A avaliação sintomatológica na película dos grãos de amendoim auxilia na seleção de novos genótipos, podendo ser mais precisa do que as avaliações visuais da parte aérea. Em alguns casos pode haver plantas atrofiadas que são sobrepostas por plantas sadias e em outros casos os sintomas podem não serem nítidos ou até mesmo não existir, sendo a planta assintomática na parte aérea. A incidência de grãos manchados apresenta correlação moderada com a incidência de plantas sintomáticas no campo (MCKINNEY, 2013).

O presente trabalho teve como objetivo avaliar manchas em grãos de amendoim, produzidos sob elevada severidade de mancha anelar, em genótipos desenvolvidos pelo Programa de Melhoramento do Amendoim da Embrapa, em Tupã-SP.

\section{Material e métodos}

O experimento foi conduzido na safra 2019/20, no município de Tupã-SP, semeado no dia 15 de novembro de 2019. Os tratos culturais e fitossanitários foram realizados conforme orientação agronômica para obter alta produtividade. As parcelas foram compostas por duas linhas de três metros de comprimento, espaçamento entre linhas de 0,90 m, intervalo entre parcelas de dois metros e área útil 5,4 m2. 
Foram avaliadas a cultivar BRS 423 OL e 26 linhagens: 18-2131 OL, 18-2584 OL, 18-2136 OL, 18-2042 OL, 18-2250 OL, 18-2133 OL, 18-2053 OL, 18-2066 OL, 18-2101 OL, 19-2533 OL, 19-2055 OL, 19-2582 OL, 182010 OL, 18-1969 OL, 18-2246 OL, 18-1952 OL, 18-1968 OL, 17-1253 OL, 18-1991 OL, 18-2182 OL, 19-2547 OL, 18-2087 OL, 18-2259 OL, 18-2717 OL, 18-1944 OL, 18-2091 OL. Todos estes genótipos foram desenvolvidos pelo Programa de Melhoramento do Amendoim da Embrapa.

A colheita foi realizada aos 122 dias após a semeadura. Após a colheita de cada tratamento foram coletadas quatro amostras de 200 gramas, em delineamento inteiramente casualizado e identificados os grãos manchados com sintomas de mancha anelar (presença de manchas irregulares, avermelhamento, rachaduras nas películas e deformações nos grãos). Foi obtida a massa e a porcentagem de grãos manchados em cada amostra de 200 gramas.

Os dados obtidos foram submetidos à análise de variância (Teste $\mathrm{F}$ ) e as médias dos tratamentos foram comparados pelo teste de Scott-Knott a $5 \%$ de probabilidade, por meio do programa computacional SISVAR 5.6 (FERREIRA, 2019).

\section{Resultados e discussão}

Houve diferença significativa para os diferentes genótipos de amendoim na massa de grãos manchados (Tabela 1). Observa-se a linhagem 18-2131 OL com a menor massa de grãos manchados $(41,9 \mathrm{~g})$, seguida pelas linhagens 19-2584 OL (53,0 g), 18-2136 OL (53,6 g), 18-2042 OL (53,7 g), 18-2250 OL (55,1 g), BRS 423 OL (62,7 g) e 18-2133 OL (62,8 g). Estes genótipos possuem de 20 a $32 \%$ dos grãos com sintomas de mancha anelar (Gráfico 1).

Valores intermediários de massa de grãos manchados foram observados nas linhagens 18-2053 OL (66,9 g), 18-2066 OL (67,0 g), 18$2101 \mathrm{OL}(68,2 \mathrm{~g}), 19-2533 \mathrm{OL}(69,2 \mathrm{~g}), 18-2055 \mathrm{OL}(73,2 \mathrm{~g}), 19-2582 \mathrm{OL}$ $(73,4 \mathrm{~g})$ e $18-2010 \mathrm{OL}(73,8 \mathrm{~g})$, correspondendo a valores entre 33 e $37 \%$ de grãos manchados. 
Tabela 1. Massa de grãos manchados de diferentes genótipos de amendoim sob alta severidade de viroses. Tupã-SP, safra 2019/20.

\begin{tabular}{|c|c|c|c|c|c|}
\hline Genótipos & $\begin{array}{l}\text { Massa de } \\
\text { grãos com } \\
\text { mancha (g) }\end{array}$ & Genótipos & $\begin{array}{l}\text { Massa de } \\
\text { grãos com } \\
\text { mancha }(\mathrm{g})\end{array}$ & Genótipos & $\begin{array}{c}\text { Massa de } \\
\text { grãos com } \\
\text { mancha (g) }\end{array}$ \\
\hline $18-2131 \mathrm{OL}$ & $41,9 a$ & $18-2101 \mathrm{OL}$ & $68,2 d$ & $17-1253 \mathrm{OL}$ & $89,2 f$ \\
\hline $19-2584 \mathrm{OL}$ & $53,0 \mathrm{~b}$ & $19-2533 \mathrm{OL}$ & $69,2 \mathrm{~d}$ & $18-1991 \mathrm{OL}$ & $90,6 \mathrm{f}$ \\
\hline $18-2136 \mathrm{OL}$ & $53,6 \mathrm{~b}$ & $18-2055$ OL & $73,2 \mathrm{~d}$ & $18-2182 \mathrm{OL}$ & $92,8 \mathrm{f}$ \\
\hline $18-2042 \mathrm{OL}$ & $53,7 \mathrm{~b}$ & $19-2582 \mathrm{OL}$ & $73,4 d$ & $19-2547 \mathrm{OL}$ & $94,2 \mathrm{f}$ \\
\hline $18-2250 \mathrm{OL}$ & $55,1 \mathrm{~b}$ & $18-2010 \mathrm{OL}$ & $73,8 d$ & $18-2087 \mathrm{OL}$ & $96,5 f$ \\
\hline BRS $423 \mathrm{OL}$ & $62,7 \mathrm{c}$ & 18-1969 OL & 80,5 e & $18-2259 \mathrm{OL}$ & $114,3 \mathrm{~g}$ \\
\hline $18-2133 \mathrm{OL}$ & $62,8 \mathrm{c}$ & $18-2246 \mathrm{OL}$ & 80,6 e & $19-2717 \mathrm{OL}$ & $115,9 \mathrm{~g}$ \\
\hline 18-2053 OL & $66,9 d$ & 18-1952 OL & 81,7 e & 18-1944 OL & $126,2 \mathrm{~h}$ \\
\hline $18-2066 \mathrm{OL}$ & $67,0 \mathrm{~d}$ & 18-1968 OL & 85,4 e & $18-2091 \mathrm{OL}$ & $129,7 \mathrm{~h}$ \\
\hline Média & & & 79,7 & & \\
\hline CV (\%) & & & 7,1 & & \\
\hline $\mathrm{Pr}>\mathrm{Fc}$ & & & $>0,0001^{*}$ & & \\
\hline
\end{tabular}

Significativo a 5\% de probabilidade pelo teste de Scott-Knott; ns - não significativo; C.V. coeficiente de variação.

As maiores massas de grãos manchados foram observadas em 13 linhagens: 18-1969 OL (80,5 g), 18-2246 OL (80,6 g), 18-1952 OL $(81,7 \mathrm{~g})$, 18-1968 OL (85,4 g), 17-1253 OL (89,2 g), 18-1991 OL (90,6 g), 18-2182 OL $(92,8 \mathrm{~g}), 19-2547 \mathrm{OL}(94,2 \mathrm{~g}), 18-2087 \mathrm{OL}(96,5 \mathrm{~g}), 18-2259 \mathrm{OL}(114,3 \mathrm{~g})$, 19-2717 OL (115,9 g), 18-1944 OL (126,2 g) e 18-2091 OL $(129,7)$, correspondendo a porcentagens superiores a $40 \%$ de grãos manchados, chegando a $65 \%$ da amostra de grãos com sintomas de mancha anelar.

Embora a correlação entre a incidência de manchas nos grãos e a incidência de plantas com sintomas de mancha anelar tenha sido relatada recentemente (MCKINNEY, 2013), é importante avaliar o desempenho agronômico destes genótipos em áreas com epidemias severas de mancha anelar, para desenvolver cultivares adaptadas e com qualidade dos grãos que atenda ao mercado do amendoim no Brasil e no exterior. 


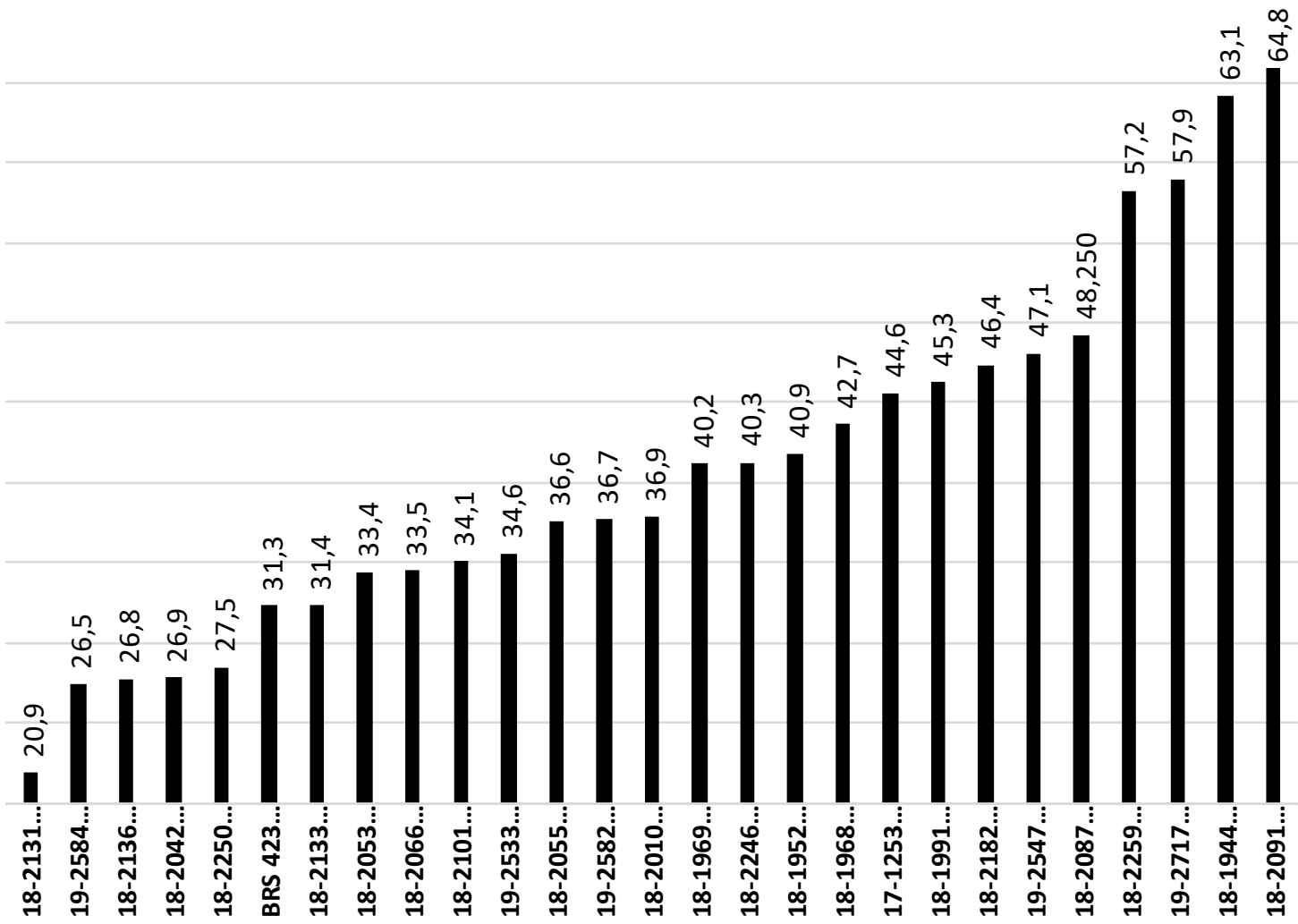

Gráfico 1. Porcentagem de manchas nos grãos na amostra, Tupã, SP, safra $2019 / 20$.

\section{Conclusões}

A linhagem 18-2131 OL apresentou a menor massa e a menor porcentagem de grãos manchados $(20,1 \%)$; as linhagens $19-2584 \mathrm{OL}$, 18 2136 OL, 18-2042 OL e 18-2250 OL apresentaram menos de $30 \%$ de manchas; a cultivar BRS 423 OL apresentou menos de 32\% de manchas nos grãos. A identificação de genótipos com menos sintomas nos grãos é importante para o desenvolvimento de cultivares de amendoim com melhor qualidade dos grãos.

\section{Agradecimentos}

Os autores agradecem a Amenco Peanuts pela Cooperação Técnica, aos produtores Antônio Fernandes e Ricardo da Silveira Fernandes pela disponibilidade da área e condução do experimento em Tupã-SP. Ao Programa de Melhoramento do Amendoim da Embrapa, vinculado ao projeto SEG 20.18.01.021.00. 


\section{Referências}

FERREIRA, D. F. SISVAR: a computer analysis system to fixed effects split plot type designs. Revista Brasileira de Biometria, [S.L.], v. 37, n. 4, p. 529, 20 dez. 2019. http://dx.doi.org/10.28951/rbb.v37i4.450.

MAGALHÃES, F. O. C.; HEUERT, J.; BAZANELLA, M. R.; SUASSUNA, N. D.; RIBEIRO, R. P.; SUASSUNA, T. M. F. Detecção de TCSV e GRSV em amostras de amendoim com sintomas de mancha anelar. In: Anais do Encontro Sobre a Cultura do Amendoim, 16., 2019, Jaboticabal. Anais eletrônicos... Campinas: GALOÁ, 2019. Disponível em: $<$ https://proceedings.science/encontro-amendoim-2019/papers/deteccao-detcsv-e-grsv-em-amostras-de-amendoim-com-sintomas-de-mancha-anelar>. Acesso em: 10 jun. 2020.

MCKINNEY, J. L. Influence of planting date, plant population, and cultivar on management of spotted wilt in peanut (Arachis hypogaea L.). 2013. 64 f. Dissertação (Mestre em Ciências). Universidade da Flórida, Gainesville, 2013.

PAPPU, S. S.; PAPPU, H. R.; CULBREATH, A. K.; TODD, W. Localization of Tomato Spotted Wilt Virus (GenusTospovirus, FamilyBunyaviridae) in Peanut Pods. Peanut Science, [S.L.], v. 26, n. 2, p. 98-100, jul. 1999. http://dx.doi.org/10.3146/i0095-3679-26-2-7.

RIBEIRO, R. P.; HEUERT, J.; SUASSUNA, N. D.; SUASSUNA, T. M. F. Desempenho de linhagens de amendoim sob alta severidade de doenças foliares. In: Anais do Encontro Sobre a Cultura do Amendoim, 14., 2017, Jaboticabal. Anais eletrônicos... Campinas: GALOÁ, 2017. Disponível em: $<$ https://proceedings.science/encontro-amendoim-2017/papers/desempenhode-linhagens-de-amendoim-sob-alta-severidade-de-doencas-

foliares?lang=pt-br>. Acesso em: 10 jun. 2020.

RIBEIRO, R. P.; HEUERT, J.; SOAVE, J. H.; SANTOS, L. C. C.; SUASSUNA, T. M. F. Avaliação de severidade de mancha preta e mancha anelar em diferentes genótipos de amendoim na região da Alta Paulista. In: Anais do Encontro Sobre a Cultura do Amendoim, 16., 2019, Jaboticabal. Anais eletrônicos... Campinas: GALOÁ, 2019. Disponível em: $<$ https://proceedings.science/encontro-amendoim-2019/papers/avaliacao-deseveridade-de-mancha-preta-e-mancha-anelar-em-diferentes-genotipos-deamendoim-na-regiao-da-alta-paulista>. Acesso em: 10 jun. 2020.

SUASSUNA, T. M. F; ALMEIDA M. M. S; RESENDE, R. O; LIMA, M. G. A; FARIA, J. C; HEUERT, J.; SUASSUNA, N. D. Identificação de Tospovírus em amostras de amendoim com sintomas de clareamento das nervuras no estado de Goiás. In: Anais do Encontro Sobre a Cultura do Amendoim, 13., 2016, Jaboticabal. Anais eletrônicos... Campinas: GALOÁ, 2016. Disponível em: <https://www.researchgate.net/publication/333951206_IDENTIFICACAO_DE _TOSPOVIRUS_EM_AMOSTRAS_DE_AMENDOIM_COM_SINTOMAS_DE 
CLAREAMENTO_DAS_NERVURAS_NO_ESTADO_DE_GOIAS>. Acesso em: 12 jun. 2020. 